\title{
Production of Itaconic Acid from Jatropha curcas Seed Cake by Aspergillus terreus
}

\author{
Amina M. AHMED EL-IMAM*, Muinat O. KAZEEM, Mutiat B. \\ ODEBISI, Mushaffau A. OKE, Azeezat O.ABIDOYE
}

University of Ilorin, Faculty of Science, Microbiology Department, P.M.B. 1515, Ilorin, Nigeria; amkmusty@yahoo.com (*correspondence author)

\begin{abstract}
Submerged substrate fermentation of Jatropha seed cake, a by-product of oil extraction from Jatropha curcas seed was carried out using Aspergillus terreus for the production of itaconic acid. The Jatropha seed cake was initially converted into fermentable sugars by dilute acid hydrolysis using 50\% sulphuric acid. The rate of hydrolysis was $1.04 \mathrm{gL}^{-1}$. The fermentation process was carried out at room temperature, agitation of $400 \mathrm{rpm}$ and three physico-chemical parameters ( $\mathrm{pH}$, inoculum size and substrate concentration) were varied. Itaconic acid and glucose assays were carried out by spectrophotometry and Dinitrosalicylic acid methods respectively daily. Maximum yield of itaconic acid was $48.70 \mathrm{gL}^{-1}$ at $5 \mathrm{ml}$ of inoculum size, $50 \%$ substrate concentration and $\mathrm{pH}$ 1.5. The residual glucose concentration increased for the first two days of fermentation after which it began to decrease as the itaconic acid concentration increased. The least concentration of itaconic acid observed was $6.00 \mathrm{gL}^{-1}$, obtained after 24 hours of fermentation with $4 \mathrm{ml}$ inoculum size, $50 \%$ substrate concentration and at $\mathrm{pH}$ 1.5. The findings of this work indicate that Jatropha curcas seed cake is a suitable substrate for itaconic acid production.
\end{abstract}

Keywords: acid hydrolysis, Aspergillus terreus, fermentation, itaconic acid, Jatropha seed cake, residual glucose

\section{Introduction}

Itaconic acid, also known as methyl succinic acid, is an unsaturated di-carboxylic organic acid (Wilke and Vorlop, 2001) with the formula $\mathrm{C}_{5} \mathrm{O}_{4} \mathrm{H}_{4}$. Its primary application is in the polymer industry where it is employed as a co-monomer for the industrial synthesis of polyesters, plastics, and artificial glass; in the preparation of bioactive compounds in the agriculture, pharmacy, and medicine sectors; coatings, acrylic fibers, detergents, adhesives, thickeners, and binders, and a range of other products. It has a potential to be used as a substitute for acrylic or methyl methacrylate, both of which are derived from petrochemicals and other industrial products (Tate, 1981).

The first reported biological source of itaconic acid was Aspergillus itaconicus. Shortly thereafter, it was discovered that $A$. terreus also produced itaconic acid in higher quantities (Meena et al., 2010) by Ustilago maydis (Chandragiri and Sastry, 2011a), various Aspergillus species and Pseudozyma antartica (Levinson et al., 2006).

Various agro-industrial wastes can be fermented for the production of itaconic acid. Jatropha curcas is also variously known as physic nut, purging nut, barbados nut, pig nut or fig nut (Encyclopedia of Fruits and Nuts, 2008), however Jatropha is both the genus and the most common name. The seeds contain anti-nutrients such as phorbolesters, trypsin inhibitors, lectins and phytate (Makkar et al., 2008), thus rendering the seed and its products inedible.
The extraction of oil from jatropha oilseeds and its conversion into biodiesel involves many complex processes in which a press-cake is a major byproduct. This cake is dark brown in color and contains carbohydrates, fibers and remaining oil and may be used as organic fertilizer because of the high content of nitrogen.

Jatropha is gaining increasing importance as an emerging source of biodiesel and this is leading to a rapid accumulation of the cake. Despite being nutrient-rich, jatropha cake is toxic and cannot be consumed by humans or animals so it is cheap and readily available. Itaconic acid is currently expensive, so alternative or cheaper substrates may make the production process more profitable.

The process of obtaining itaconic acid from jatropha cake like other plant biomass wastes involves three important steps- mechanical processing and pretreatment of the material to expose the cellulose and hemi-cellulose components; enzymatic or chemical hydrolysis of the pretreated material to produce reducing sugars such as glucose; and finally fermentation of the hydrolyzed material by a suitable microorganism to produce the desired acid (Zheng et al., 2009).

The objectives of this work are to determine the suitability of Jatropha curcas seed cake as a cellulosic substrate for the fermentative production of itaconic acid, to determine the ability of Aspergillus terreus to utilize Jatropha curcas seed cake as substrate for itaconic acid production and lastly, to determine the optimum levels of parameters 
58

such as substrate concentration, $\mathrm{pH}$ and inoculum size for itaconic acid production.

\section{Materials and methods}

Preparation of jatropha seed cake (JSC)

Jatropha curcas seeds were collected from Iwo, Osun state, and some markets in Kwara state, Nigeria. The cakes were initially crushed to $0.5-0.6$ inches and soaked in water overnight to remove dirt and excess oil. The oil slowly left the cake to float on the water surface. The cakes were then separated from the dirty water using a sieve and dried in air (Mohit et al., 2011).

\section{Collection of microorganisms}

Aspergillus terreus was obtained from the Federal Institute of Industrial Research Oshodi (FIIRO), Lagos state, Nigeria. The culture was maintained on potato dextrose agar (PDA) slants and kept at temperature of about $4^{\circ} \mathrm{C}$ prior to use.

\section{Sucrose broth pre-culture medium}

Nutrient broth medium was prepared according to the manufacturer's specifications and was supplemented with $0.5 \mathrm{~g}$ sucrose. The broth was then sterilized in an autoclave at $121^{\circ} \mathrm{C}$ for 15 minutes at 15 psi. The sucrose broth was then inoculated with a loop full of Aspergillus terreus (Mohit, 2011; Rao, 2007).

\section{Pre-treatment}

The size of the oil cakes was mechanically reduced using a grinder and a fine powder of 4.0 mesh size was obtained. The powder was dried in an oven at $45^{\circ} \mathrm{C}$ for 2 hours to completely remove the moisture. Equal volume of $0.5 \% \mathrm{H}_{2} \mathrm{SO}_{4}$ was added and the mixture was autoclaved at $121^{\circ} \mathrm{C}$ for 15 minutes at 15 psi. The mixture was again dried with warm air at $30-35^{\circ} \mathrm{C}$ (Mohit, 2011). Samples were collected from the pre-treated material for analysis.

\section{Hydrolysis}

The raw materials were hydrolyzed by dilute acid hydrolysis method. Twice the volume of $5 \% \mathrm{H}_{2} \mathrm{SO}_{4}$ was added to the pre-treated material and mixed thoroughly. The mixture was poured in glass bottles and sealed to prevent vaporization of acid due to heat. The mixture was kept at a high temperature of $55^{\circ} \mathrm{C}$ for three days and was mixed regularly to prevent precipitation. Samples were collected from the hydrolyzed material daily for relevant analyses (Mohit, 2011).

\section{Fermentation medium}

Specific quantities of Jatropha seed cake were mixed in $100 \mathrm{ml}$ of distilled water (Bresslen and Braun, 2000), $3 \mathrm{~g}$ $\mathrm{NaNO}_{3}, 1 \mathrm{~g} \mathrm{~K}_{2} \mathrm{HPO}_{4}, 0.8 \mathrm{~g} \mathrm{MgSO}_{4}, 0.01 \mathrm{~g} \mathrm{FeSO}_{4}, 0.5 \mathrm{~g}$ $\mathrm{KCl}$, were added to the medium. The hydrolyzed medium was dispensed in bottles and sterilized in an autoclave at $121^{\circ} \mathrm{C}$ for 15 minutes at 15 psi. It was then inoculated with specific quantities of the spore suspensions, closed and incubated at room temperature on a rotary shaker at $400 \mathrm{rpm}$. Different parameters like inoculum size, substrate concentrations and $\mathrm{pH}$ were varied. The fermentation was continued for 15 days and samples were analyzed daily for residual glucose and itaconic acid (Mohit, 2011; Rao, 2007).

\section{Variation offermentation parameters}

\section{$-p H$}

The $\mathrm{pH}$ of the solution was adjusted to desired value by the addition of nitric acid and sodium hydroxide to $\mathrm{pH}$ values 2.0, 2.5, 3.0, 3.5 and 4.0. Other parameters were kept constant at $50 \%$ JSC concentration and inoculum size of $5 \%$.

\section{-Substrate concentration}

This was varied at 10, 25, 40 and $50 \%$ of JSC in sterile distilled water. The $\mathrm{pH}$ was held at 1.55 and $5 \%$ inoculum size.

\section{-Inoculum size}

Spore suspension containing about $9.3 \times 10^{6}$ spores per $\mathrm{ml}$ suspension were prepared according to the method of Pertruccioli et al. (1989) and used as inoculum for the fermentation process. This was varied from $1-5 \mathrm{ml}$ to determine the effect of inoculum size on fermentative production of itaconic acid. The $\mathrm{pH}$ and substrate concentration were held at 1.55 and $50 \mathrm{~g}$ respectively.

\section{Analytical methods and calculations}

Samples were collected daily. Glucose was estimated by Dinitrosalicylic acid (DNS) method and absorbance measured at $575 \mathrm{~nm}$ (Miller, 1959). The corresponding concentrations were obtained from a standard graph drawn from glucose standards. In this way, sugar estimation was done in the oilseed cakes before and after pretreatmenthydrolysis stage. Rate of hydrolysis was calculated using the formular of Arthe et al. (2008) and was used for calculating these two parameters:

$$
\text { Rate of hydrolysis }=\frac{{\text { Glu } \cos e_{\mathrm{t}}}_{\mathrm{t}}-{\mathrm{Glu} \cos \mathrm{e}_{\mathrm{t}_{0}}}_{\mathrm{t}-\mathrm{t}_{0}}}{\mathrm{t}}
$$

Where Glucose is the concentration of glucose after time $t$, and Glucose $e_{t 0}$ is the concentration of glucose before hydrolysis. $t$ and $t_{0}$ are the final and initial time in hours respectively.

The itaconic acid produced was estimated by spectrophotometry (Meena et al., 2010), and the absorbance was read at $385 \mathrm{~nm}$, and again at 20 minutes to ascertain the reaction had gone to completion. The itaconic acid concentrations were then determined from standard graphs.

The data obtained after analysis were statistically analyzed by one way ANOVA. The experiments were dupli- 
cated and the means were separated by Duncan's Multiple Range Test.

\section{Results and discussion}

\section{Hydrolysis of JSC}

The glucose content of the un-hydrolyzed and hydrolyzed JSC were $0.52 \mathrm{mg} / \mathrm{g}$ and $18.60 \mathrm{mg} / \mathrm{g}$ respectively. The rate of hydrolysis was $1.04 \mathrm{~g} \mathrm{~g}^{-1} \mathrm{~kg}^{-1} \mathrm{hr}$. There was a significant increase $(p<0.05)$ in the reducing sugar content of unhydrolyzed and hydrolyzed JSC and was estimated to be $0.014 \mathrm{mg} / \mathrm{ml}$ and $0.089 \mathrm{mg} / \mathrm{g}$ of the sample respectively. This is similar to the result obtained by Mohit et al. (2011) who observed that high volume of glucose was produced in the medium containing cellulose after three days hydrolysis with $5 \%$ sulfuric acid.

The highest quantity of itaconic acid, $48.70 \mathrm{~g} / \mathrm{L}$, was produced at $\mathrm{pH} 1.55$, inoculum size $5 \mathrm{ml}$, substrate concentration of $50 \mathrm{~g}$ in $100 \mathrm{ml}$ and aeration rate of $400 \mathrm{rpm}$, at room temperature and this was obtained on the $9^{\text {th }}$ day of fermentation. This figure compares favourably with the values such as $60 \mathrm{gL}^{-1}$ obtained by Yahiro et al. (1997) 20 $\mathrm{gL}^{-1}$ obtained by Klement et al. (2012), $24.45 \mathrm{gL}^{-1}$ by Rao et al. (2007) and $97.14 \mathrm{gL}^{-1}$ by Chandragiri and Sastry (2011a). The lowest quantity of the acid was $6.00 \mathrm{~g} / \mathrm{L}$ produced after 24 hours of fermentation with $4 \mathrm{ml}$ inoculum size.

\section{Effect of $p H$ on fermentation}

$\mathrm{pH}$ is one of the most important parameters that affect the production of itaconic acid by fermentation. Fermentable medium with adjusted $\mathrm{pH}$ of 2, 2.5, 3.5 and 4 were observed over a period of 15 days and maximum yield was obtained at all $\mathrm{pH}$ levels on Day 10 of fermentation with $\mathrm{pH} 4$ yielding the highest itaconic acid concentration of $38.70 \mathrm{gL}^{-1}$ (Tab. 1). This is close to the findings of Rao et al. (2007) and Chandragiri and Sastry (2011b) who reported the highest production of itaconic acid at $\mathrm{pH} 3.5$ and 3 respectively. Production began to decline from Day 11 with the lowest itaconic acid production of $8.50 \mathrm{gL}^{-1}$ obtained at day 14 as a result of the exhaustion of nutrient in the medium indicated by the low sugar in the medium (Fig. 1). Both the internal and environment's proton concentra-

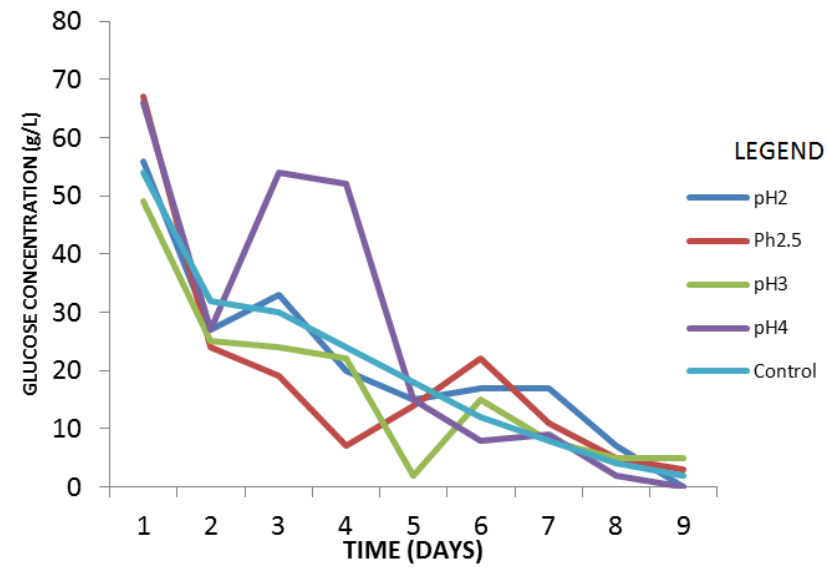

Fig. 1. Residual glucose in the fermentation at different $\mathrm{pH}$

tions play a significant role on the growth and metabolism of a microorganism (Chandragiri and Sastry, 2011b); as a result microorganisms have evolved mechanisms to maintain relatively constant intracellular $\mathrm{pH}$ values, regardless of the $\mathrm{pH}$ of the external environment. However, when $\mathrm{pH}$ differs from what is optimal for any particular species, there will be an increase in maintenance energy required to maintain optimal intracellular $\mathrm{pH}$ and this may adversely affect the desired metabolite's production reflected in this research by declining yields of itaconic acid. This is similar to the report of Mohit et al. (2011) that the concentration of glucose broth was estimated to be around $9.75 \mathrm{mg} / \mathrm{ml}$ in the hydrolyzed Jatropha press cake which was reduced to $5.85 \mathrm{mg} / \mathrm{ml}$ at the end of fermentation.

\section{Effect of inoculum size on fermentation}

Inoculum size is a major factor that determines the course of fungal fermentation. Inoculum sizes of 1, 2, 3, 4 and $5 \mathrm{ml}$ were used for the fermentation of JSC to determine the optimum inoculum size for itaconic acid production at $50 \%$ substrate concentration, $\mathrm{pH} 1.55$, ambient temperatures and aeration of $400 \mathrm{rpm}$. Maximum itaconic acid was obtained with $5 \mathrm{ml}$ of spore suspension $(48.70 \mathrm{gL}$ $\left.{ }^{1}\right)$ on the Day 9 of fermentation as shown in Fig. 2, even though there was no statistically significant difference $(p<$ 0.05 ) from the values observed at 2,3 , and $4 \mathrm{ml}$ of spore suspensions. This is similar to the findings of Chandragiri and Sastry (2011b), who observed that maximum produc-

Tab. 1. Itaconic acid production at different $\mathrm{pH}$ of fermentation

\begin{tabular}{cccccccccc}
\hline \multirow{2}{*}{$\mathrm{pH}$} & \multicolumn{7}{c}{ Itaconic acid production $(\mathrm{g} / \mathrm{L})$ at different incubation time } \\
\cline { 2 - 9 } & Day 2 & Day3 & Day 4 & Day 7 & Day 8 & Day 9 & Day 10 & Day 13 & Day 14 \\
\hline $\mathrm{pH} 2.0$ & $12.20 \pm 0.351^{\mathrm{b}}$ & $13.00 \pm 0.52^{\mathrm{c}}$ & $19.50 \pm 3.92^{\mathrm{c}}$ & $20.00 \pm 1.36^{\mathrm{bc}}$ & $24.00 \pm 2.04^{\mathrm{a}}$ & $24.50 \pm 0.11^{\mathrm{a}}$ & $37.00 \pm 0.75^{\mathrm{d}}$ & $24.00 \pm 0.37^{\mathrm{d}}$ & $8.50 \pm 0.22^{\mathrm{a}}$ \\
$\mathrm{pH} 2.5$ & $12.00 \pm 0.59^{\mathrm{b}}$ & $16.00 \pm 0.83^{\mathrm{c}}$ & $23.50 \pm 0.82^{\mathrm{d}}$ & $14.50 \pm 1.68^{\mathrm{a}}$ & $28.70 \pm 0.39^{\mathrm{b}}$ & $29.50 \pm 0.41^{\mathrm{b}}$ & $31.20 \pm 0.182^{\mathrm{c}}$ & $19.20 \pm 0.816^{\mathrm{c}}$ & $11.20 \pm 0.365^{\mathrm{cd}}$ \\
$\mathrm{pH} 3$ & $11.50 \pm 2.16^{\mathrm{b}}$ & $14.50 \pm 0.91^{\mathrm{d}}$ & $19.20 \pm 0.14^{\mathrm{c}}$ & $21.70 \pm 4.20^{\mathrm{c}}$ & $24.10 \pm 0.28^{\mathrm{a}}$ & $24.50 \pm 0.41^{\mathrm{a}}$ & $22.00 \pm 1.41^{\mathrm{b}}$ & $11.70 \pm 0.16^{\mathrm{a}}$ & $10.00 \pm 0.93^{\mathrm{ab}}$ \\
$\mathrm{pH} 4$ & $19.10 \pm 0.08^{\mathrm{a}}$ & $16.60 \pm 0.55^{\mathrm{a}}$ & $13.00 \pm 0.18^{\mathrm{a}}$ & $19.70 \pm 0.22^{\mathrm{b}}$ & $23.50 \pm 0.82^{\mathrm{a}}$ & $24.50 \pm 0.42^{\mathrm{a}}$ & $38.70 \pm 0.16^{\mathrm{c}}$ & $20.00 \pm 0.99^{\mathrm{c}}$ & $11.50 \pm 0.14^{\mathrm{d}}$ \\
Control & $9.50 \pm 0.21^{\mathrm{a}}$ & $11.70 \pm 0.16^{\mathrm{b}}$ & $14.50 \pm 2.45^{\mathrm{b}}$ & $18.20 \pm 1.41^{\mathrm{b}}$ & $24.50 \pm 0.34^{\mathrm{a}}$ & $28.00 \pm 0.26^{\mathrm{b}}$ & $19.00 \pm 0.36^{\mathrm{a}}$ & $15.20 \pm 0.28^{\mathrm{b}}$ & $10.20 \pm 0.44^{\mathrm{bc}}$ \\
\hline
\end{tabular}

Other conditions were kept constant: $5 \mathrm{ml}$ Inoculum size and $50 \mathrm{~g}$ of substrate concentration. The control is at $\mathrm{pH} 1.55$

The values are mean of four replicates \pm standard deviation. Values with different superscripts within the same column show significant difference $(p<0.05)$ 
60

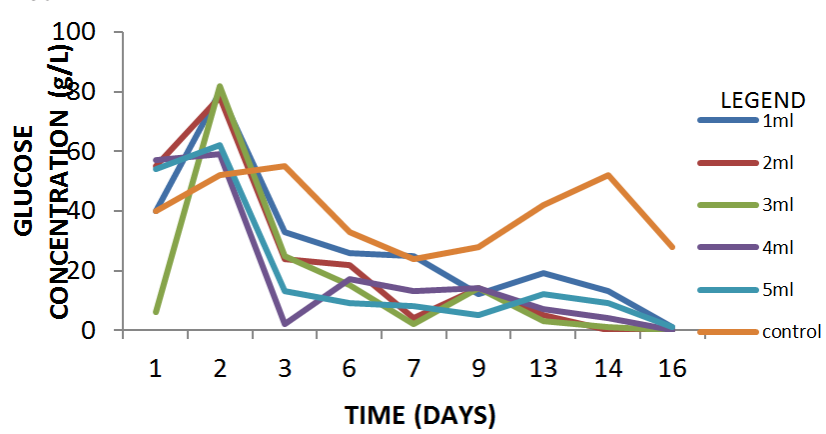

Fig. 2. Residual glucose during the fermentation with different inoculum sizes

tion of itaconic acid was obtained with $5 \mathrm{ml}$ of inoculum size of Ustilago maydis. This observation implies more of the organism produces more itaconic acid and this also explains the reduction in reducing sugar $\left(0.005 \mathrm{gL}^{-1}\right)$ during fermentation with this inoculum size (Tab. 2). The lowest production of itaconic acid was $6.00 \mathrm{mg} / \mathrm{ml}$ on $4 \mathrm{ml}$ inoculum after 24 hours of fermentation.

It was also observed that residual glucose increased in the first two days before the concentration began to decline. This observation is in line with what Mohit et al. (2011) observed during production of ethanol by Saccharomyces cerevisiae using Jatropha curcas seed cake that the rate of consumption of glucose is lower in the first 4 days of fermentation, but picks up in later days. This is probably because the hydrolysis of the JSC is proceeding with time, thus liberating more sugars from the cake because the organism was undergoing a lag phase while adjusting to the new environment of the fermentation medium. This also explains the low itaconic acid quantities observed on Day 1 during the various experiments and the rapid increase on Day 2 (Fig. 1-3).

Tab. 2. Effect of inoculum size on itaconic acid production

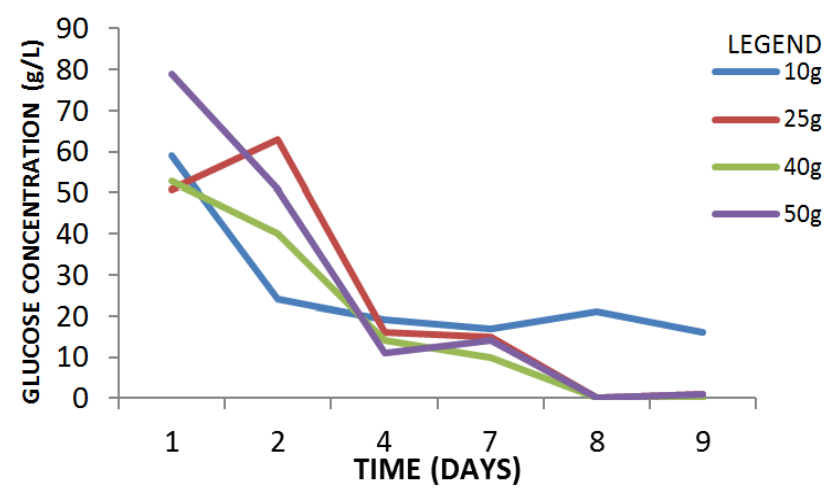

Fig. 3. Residual glucose in the fermentation at different substrate concs

\section{Effect of varying substrate concentration}

A comparative account of production of itaconic acid using Jatropha curcas seed cake at different concentrations i.e. $10 \%, 25 \%, 40 \%$ and $50 \%$ using $A$. terreus was also studied. The maximum production of itaconic acid obtained was $31.70 \mathrm{~g} / \mathrm{L}$ at Day 7 of fermentation with $40 \%$ JSC (Tab. 3).

This result is similar to that of Chandragiri and Sastry (2011b) who obtained maximum production of itaconic acid on 35\% concentration of pure glucose. This value was significantly higher than that of other concentrations on the same day. The lowest production of itaconic acid is $8.00 \mathrm{~g} / \mathrm{L}$ with $10 \mathrm{~g}$ substrate concentration which is to be expected because of the low JSC concentration and also, it was on the first day of fermentation where there may be a lag phase. It was observed that with increase in itaconic acid production, there was a corresponding decrease in glucose concentration (Fig. 3).

\begin{tabular}{|c|c|c|c|c|c|c|c|c|c|}
\hline \multirow{2}{*}{$\begin{array}{c}\text { Inoculum } \\
\text { Size }\end{array}$} & \multicolumn{9}{|c|}{ Itaconic acid production $(\mathrm{g} / \mathrm{L})$} \\
\hline & Day 1 & Day2 & Day3 & Day6 & Day7 & Day9 & Day13 & Day14 & Day15 \\
\hline $1 \mathrm{ml}$ & $8.00 \pm 0.18^{\mathrm{b}}$ & $9.50 \pm 0.26^{a}$ & $10.20 \pm 0.08^{b}$ & $12.50 \pm 0.91^{\mathrm{b}}$ & $39.00 \pm 0.43^{c}$ & $42.00 \pm 1.47^{b}$ & $32.00 \pm 0.91^{\mathrm{b}}$ & $35.50 \pm 2.25^{\mathrm{c}}$ & $32.20 \pm 0.18^{\mathrm{d}}$ \\
\hline $2 \mathrm{ml}$ & $9.50 \pm 1.25^{c}$ & $10.50 \pm 0.41^{\mathrm{b}}$ & $19.70 \pm 0.16^{\mathrm{d}}$ & $20.70 \pm 0.18^{c}$ & $33.50 \pm 0.26^{c}$ & $47.00 \pm 1.10^{c}$ & $35.10 \pm 0.18^{\mathrm{bc}}$ & $26.60 \pm 0.37^{b}$ & $12.00 \pm 3.39^{\mathrm{b}}$ \\
\hline $3 \mathrm{ml}$ & $10.70 \pm 0.18^{c}$ & $12.20 \pm 0.50^{c}$ & $12.20 \pm 0.32^{c}$ & $10.20 \pm 0.14^{\mathrm{c}}$ & $32.00 \pm 1.47^{\mathrm{b}}$ & $47.70 \pm 0.18^{\mathrm{cd}}$ & $37.20 \pm 0.14^{c}$ & $37.00 \pm 0.91^{\mathrm{d}}$ & $14.50 \pm 2.08^{b}$ \\
\hline $4 \mathrm{ml}$ & $6.00 \pm 0.832^{\mathrm{a}}$ & $13.70 \pm 0.83^{\mathrm{d}}$ & $10.50 \pm 0.03^{b}$ & $21.20 \pm 0.18^{\mathrm{a}}$ & $35.10 \pm 0.14^{\mathrm{d}}$ & $48.00 \pm 0.18^{\mathrm{cd}}$ & $36.00 \pm 0.41^{\mathrm{c}}$ & $33.70 \pm 0.91^{\mathrm{d}}$ & $26.10 \pm 0.91^{\mathrm{b}}$ \\
\hline $5 \mathrm{ml}$ & $17.20 \pm 0.73^{c}$ & $27.00 \pm 0.43^{\mathrm{c}}$ & $21.10 \pm 0.03^{\mathrm{c}}$ & $23.50 \pm 0.44^{\mathrm{d}}$ & $31.70 \pm 0.36^{\mathrm{b}}$ & $48.70 \pm 0.41^{\mathrm{d}}$ & $35.00 \pm 0.48^{\mathrm{bc}}$ & $38.60 \pm 0.37^{d}$ & $24.80 \pm 0.37^{c}$ \\
\hline Control & $6.00 \pm 0.83^{a}$ & $8.50 \pm 0.29^{a}$ & $6.00 \pm 0.83^{\mathrm{a}}$ & $8.50 \pm 0.09^{a}$ & $9.70 \pm 0.29^{a}$ & $8.00 \pm 0.18^{\mathrm{a}}$ & $10.80 \pm 0.47^{a}$ & $9.50 \pm 0.26^{a}$ & $9.30 \pm 0.41^{\mathrm{a}}$ \\
\hline
\end{tabular}

Other conditions were kept constant: $\mathrm{pH} 1.55$ and $50 \mathrm{~g}$ of substrate concentration. The values are mean of four replicates \pm standard deviation. Values with different superscripts within the same column show significant difference $(p<0.05)$

Tab. 3. Itaconic acid estimation at different substrate concentration

\begin{tabular}{ccccccc}
\hline \multirow{2}{*}{$\begin{array}{c}\text { Substrate } \\
\text { concentration }\end{array}$} & Itaconic acid production $(\mathrm{g} / \mathrm{L})$ \\
\cline { 2 - 6 } & Day 1 & Day2 & Day4 & Day7 & Day9 & Day10 \\
\hline $10 \%$ & $8.000 \pm 0.036^{\mathrm{b}}$ & $10.00 \pm 0.056^{\mathrm{a}}$ & $15.001 \pm 0.018^{\mathrm{b}}$ & $17.00 \pm 0.083^{\mathrm{a}}$ & $9.000 \pm 0.028^{\mathrm{a}}$ & $7.100 \pm 0.018^{\mathrm{a}}$ \\
$25 \%$ & $15.10 \pm 0.018^{\mathrm{a}}$ & $17.00 \pm 0.036^{\mathrm{b}}$ & $8.100 \pm 0.014^{\mathrm{a}}$ & $25.20 \pm 0.052^{\mathrm{b}}$ & $20.10 \pm 0.018^{\mathrm{b}}$ & $13.0 \pm 0.018^{\mathrm{b}}$ \\
$40 \%$ & $18.50 \pm 0.082^{\mathrm{b}}$ & $20.00 \pm 0.036^{\mathrm{c}}$ & $20.50 \pm 0.030^{\mathrm{d}}$ & $31.70 \pm 0.018^{\mathrm{c}}$ & $30.00 \pm 0.044^{\mathrm{c}}$ & $16.60 \pm 0.052^{\mathrm{c}}$ \\
$50 \%$ & $20.60 \pm 0.036^{\mathrm{c}}$ & $21.00 \pm 0.055^{\mathrm{c}}$ & $19.70 \pm 0.016^{\mathrm{c}}$ & $26.70 \pm 0.026^{\mathrm{a}}$ & $32.00 \pm 0.088^{\mathrm{d}}$ & $18.00 \pm 0.036^{\mathrm{d}}$ \\
\hline
\end{tabular}

Other conditions were kept constant: $\mathrm{pH} 1.55$ and $5 \mathrm{ml}$ inoculum size. The values are mean of four replicates \pm standard deviation. Values with different superscripts within the same column show significant difference $(p<0.05)$ 


\section{Conclusions}

Jatropha seed cake (JSC) has been shown to be suitable for the fermentative production of itaconic acid. This work shows that the substrate concentration, incubation time, inoculum size and $\mathrm{pH}$ all affect the production of itaconic acid on Jatropha seed cake and the optimized physico-chemical parameters for fermentation of Jatropha Seed Cake for the production of itaconic acid are: $\mathrm{pH} 4$ inoculum size of $5 \mathrm{ml}$ and JSC concentration of $40 \%$. As the cake which is a waste byproduct of the biodiesel production process accumulates over time, it can be utilized in a bid for value addition, as a good raw material for itaconic acid production and at the same time, solve the problem of safe disposal of the waste.

\section{Acknowledgements}

The authors will like to thank Mr. Remi and Mr. Ajani and for their support during the conduct of this research.

\section{References}

Arthe R, Rajesh R, Rajesh EM, Rajendran R, Jeyachandran J (2008). Production of bioethanol from cellulosic cotton waste through microbial extracellular enzymatic hydrolysis and fermentation. EJEAF Che 7(6):2984-2992.

Bresslen E, Braun S (2000). Conversion of citric acid to itaconic acid in novel liquid membrane bioreactor. J Chem Technol Biotechnol 75:66-72.

Chandragiri R, Sastry RC (2011a). Selection of media components for optimization in the synthesis of itaconic acid by plakette-burmann design. Internat J Chem Sci Applic 2 (3):200-206.

Chandragiri R, Sastry RC (2011b). Synthesis of itaconic acid using Ustilago maydis. Canadian J Chem Eng Technol 2(7):128-135.

Klement T, Milker S, Jäger G, Grande PM, de María P, Büchs J (2012). Biomass pretreatment affects Ustilago maydis in producing itaconic acid. Microb Cell Fact 11:43.
Levinson WE, Kurtzman CP, Kuo TM (2006). Production of itaconic acid by Pseudozyma antarctica NRRL Y-7808 under nitrogen-limited growth conditions. Enzyme Microbial Technol 39:824-827.

Makkar HPS, Francis G, Becker K (2008).Protein concentrate from Jatropha curcas screw-pressed seed cake and toxic and antinutritional factors in protein concentrate. J Sci Food Agric 88:1542-1548.

Meena V, Sumanjali, A, Dwarka K, Subburathinam KM, Sambasiva Rao KRS (2010). Production of itaconic acid through submerged fermentation employing different species of Aspergillus. Rasayan J Chem 16(3-1):100-109.

Mohit SM, Chandrashekhar B, Tanushree C, Kanwal S (2011). Production of bio-ethanol from jatropha oilseed cakes via dilute acid hydrolysis and fermentation by Saccharomyces cerevisiae. Internat J Biotechnol Applic Vol. 3.

Paul RE (2008). Encyclopedia of fruits and nuts. Cabi Publishing. U.S.A., $371 \mathrm{p}$.

Rao DM, Jaheer Hussain SMD, Rangadu PV, Subramanyam K, Sivarama Krishna G, Swamy AVN (2007). Fermentative production of itaconic acid by Apergillus terreus using Jatropha seed cake. Afr J Biotechnol 6(18):2140-2142.

Tate BE (1981). Itaconic acid and derivatives, 865-873 p. In: Grayson M, Eckroth E (Eds.). Kirk-Othmer: Encyclopedia of Chemical Technology, vol. 3, Wiley, New York,

Willke T, Vorlop TD (2001). Biotechnological production of itaconic acid. Appl Microbiol Biotechnol 56:289-295.

Yahiro K, Shibata S, Jia S, Park Y, Okabe M (1997). Efficient itaconic acid production from raw corn starch. J Ferment Bioeng 84(4):375-377.

Zheng Y, Pan Z, Zhang R (2009). Overview of biomass pretreatment for cellulosic ethanol production. Int J Agric Biol Eng 2(3):51-68. 